\title{
STUDY OF THE INFLUENCE OF COLD WORKING ON MECHANICAL BEHAVIOR AND DUCTILE FRACTURE OF 5754 ALUMINUM ALLOY: EXPERIMENTAL AND NUMERICAL SIMULATIONS
}

\author{
WAFA TAKTAK \\ Laboratoire des Systemes Electro-mecaniques (LASEM), National School of Engineers of Sfax, Tunisia \\ e-mail:wafa.taktak@yahoo.fr \\ Rim TAKTAK, NADDER HADDAR \\ Laboratoire Genie des Materiaux et Environnement (LGME), National School of Engineers of Sfax, Tunisia \\ RiadH Elleuch \\ Laboratoire des Systemes Electro-mecaniques (LASEM), National School of Engineers of Sfax, Tunisia
}

\begin{abstract}
The ductile damage of automotive aluminum sheet alloy AA5754-H111 is investigated by experiments and numerical simulation using the Gurson-Tvergaard-Needleman (GTN) model. The GTN parameters were determined by a uni-axial tensile test and the inverse finite element method. The same parameters were employed to provide the ductile damage behavior of central cracked panel (CCP) specimens. A good prediction can be established among the numerical simulation and experimental data in from of the force opening displacement. As an application, the identified GTN model is used to predict the influence of cold working on deformation and ductile damage. The numerical simulation results obtained are assimilated with experimental data.
\end{abstract}

Keywords: GTN model, ductile fracture, AA5754-H111, cold working

\section{Introduction}

In automotive applications, the aluminum alloys are extensively used for obtaining light mass and high strength structures. Aluminum-Magnesium (Al-Mg) aluminum alloys, indicated by 5xxx series, have a very good formability but a relativity low strength. This series of alloys strengthen only by work hardening (Burger et al., 1995). The results of investigation of mechanical damage of 5754-H111 aluminum alloy has indicated that damage and fracture are mostly results of nucleating, growing and coalescing of micro cavities or micro voids. In order to predict the ductile fracture process, several theoretical models using local approaches have been presented in the literature (Betegon et al., 1997; Corigliano et al., 2000; Imad et al., 2003; Achouri et al., 2012). So, the selection of an adapted micromechanical model allows understanding of the fracture mechanism of 5457-H111 aluminum alloy. The basic research was started by McClintock (1968) and afterwards by Rice and Tracey (1969) who investigated the growth of cylindrical and spherical voids in ductile solids. Founded on theses analysis, Gurson (1977) proposed a micromechanical approach model. Later, the Gurson model was modified by Tvergaard and Needleman (1984) by introducing parameters $q_{1}$ and $q_{2}$. They founded the void fusion equation $f^{*}$ to describe ductile failure by nucleation, growth and coalescence of spherical micro voids. Generally, the modified Gurson model is named the GTN model. Many researchers have used the GTN model to provide ductile porous materials. Benseddiq and Imad (2007) used the GTN damage model to investigate ductile tearing of 2024-T351 aluminum alloy. Oh et al. (2007) proposed a phenomenological model of ductile fracture for API X65 using the GTN model. Yan et al. (2013) employed the GTN damage model to study the initiation and propagation of the crack near the edge under 
rolling condition. Guo et al. (2013), Zhang et al. (2000), Huang et al. (2007) and Hu et al. (2014) used numerical results and experimental data to obtain parts of the GTN parameters. Unknown parameters of the model were obtained by using the inverse finite element method.

In the present research, ductile tearing of 5754 aluminum alloy has been analyzed by using the GTN model. The GTN parameters are identified by combining uni-axial tensile tests and detailed finite element analyses. The identified parameters have been employed to predict ductile failure of central cracked panel specimens. A good agreements can be established between the numerical and experimental results in form of the force versus displacement curves. As an application, the calibrated model is used to measure the cold working influence on deformation and fracture of 5754 aluminum alloy. The theoretical results are compared with experimental ones in the case of cold worked tensile and central cracked panels (CCP).

\section{The GTN model}

Gurson (1977) proposed a model to describe damage of ductile materials based on a micromechanical approach to porous plastic solids. This model takes into account degradation of the load carrying capacity due to the presence of porosity in isotropic materials. The original Gurson model was modified by Tvergaard and Needleman (1984) who relied on the coalescence of voids. The yield surface is presented by

$$
\Phi\left(\sigma_{y}, \sigma_{e q}, f\right)=\frac{\sigma_{e q}^{2}}{\sigma_{y}^{2}}+2 f^{*} q_{1} \cosh \left(\frac{3}{2} q_{2} \frac{\sigma_{m}}{\sigma_{y}}\right)-\left[1+q_{3}\left(f^{*}\right)^{2}\right]=0
$$

where $q_{1}, q_{2}$ and $q_{3}=\left(q_{1}\right)^{2}$ are the constitutive parameters incorporated by Tvergaard (1981) to amplify the hydrostatic stress effect for all strain levels. $\sigma_{e q}$ is the conventional von Mises

equivalent stress defined by: $\sigma_{e q}=\sqrt{\frac{3}{2} S_{i j} S_{i j}}\left(S_{i j}\right.$ is the stress deviator) and $\sigma_{y}$ is the yield stress of the undamaged matrix material.

For good prediction of the effect of void coalescence, Tvergaard and Needlemen (1984) introduced the damage function $f *$ defined as follows

$$
f^{*}(f)= \begin{cases}f & \text { for } f<f_{c} \\ f_{c}+\delta\left(f-f_{c}\right) & \text { for } f_{c} \leqslant f \leqslant f_{F} \\ f_{u}^{*} & \text { for } f \geqslant f_{F}\end{cases}
$$

where $\delta=\left(f_{u}^{*}-f_{C}\right) /\left(f_{F}-f_{C}\right)$ is the void growth acceleration factor, $f_{c}$ is the critical value of the void volume fraction corresponding to the beginning of the void coalescence, $f_{u}^{*}=1 / q_{1}$ is the ultimate value of the void volume fraction when the material load capacity is reduced to zero, $f_{F}$ is the final void volume fraction.

The evolution of the void volume fraction $f$ during plastic deformation is assumed to be a result of both the void growth and new voids nucleation given by

$$
\dot{f}=f_{\text {nucleation }}+f_{\text {growth }}
$$

Nucleation is considered to depend exclusively on the effective strain of the matrix material and can be estimated by the following equation

$$
f_{\text {nucleation }}=A \dot{\varepsilon}_{e q}^{p}
$$

where $\dot{\varepsilon}_{e q}^{p}$ is the equivalent plastic strain rate. 
The parameter $A$ is defined as a function of the matrix equivalent plastic strain

$$
A=\frac{f_{n}}{S_{n} \sqrt{2 \pi}} \exp \left(-\frac{1}{2}\left(\frac{\varepsilon^{p}-\varepsilon_{n}}{S_{n}}\right)^{2}\right)
$$

where $f_{n}$ is the volume fraction of void nucleating particles, $\varepsilon_{n}$ is the mean void nucleation strain, $S_{n}$ is the corresponding standard deviation and $\varepsilon_{p}$ is the effective plastic strain.

The void growth is a function of the plastic strain rate, such that

$$
\dot{f}_{\text {growth }}=(1-f) \dot{\varepsilon}_{k k}^{p}
$$

where $\dot{\varepsilon}_{k k}^{p}$ is the plastic part of the strain rate tensor.

\section{Experimental results}

In the present investigation, $2.45 \mathrm{~mm}$ in thickness 5754 aluminium alloy sheets have been used. The chemical composition of this alloy is given in Table 1.

Table 1. Chemical composition of the studied 5754-H111 aluminum alloy (wt\%, rest: Al)

\begin{tabular}{|c|c|c|c|c|c|c|c|}
\hline $\mathrm{Si}$ & $\mathrm{Fe}$ & $\mathrm{Cu}$ & $\mathrm{Mn}$ & $\mathrm{Mg}$ & $\mathrm{Cr}$ & $\mathrm{Zn}$ & $\mathrm{Ti}$ \\
\hline \hline 0.40 & 0.40 & 0.1 & 0.5 & $2.6-3.6$ & 0.3 & 0.2 & 0.15 \\
\hline
\end{tabular}

Tensile testing has been performed at room temperature using a 50KN LLOYD universal test machine (Fig. 1). The tensile specimens have been stretched in the rolling direction (RD), the transversal direction (TD) and the diagonal direction (DD $45^{\circ}$ between RD and TD) of the sheets. For each condition, three specimens have been tested at a constant speed of $1 \mathrm{~mm} / \mathrm{min}$. During testing, the axial displacement was monitored using an axial extensometer with length of $25 \mathrm{~mm}$. The geometry and dimensions of the employed specimen work are presented in Fig. 2a.

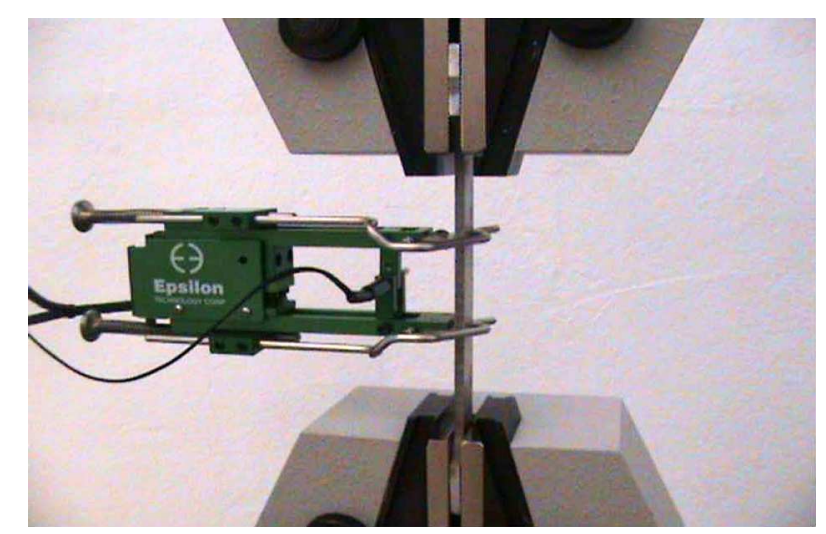

Fig. 1. Configuration of tensile tests

The uniaxial plastic flow behavior has been assumed to follow the Ramberg-Osgood stress-strain law presented as follows

$$
\varepsilon=\varepsilon_{e}+\varepsilon_{p} \quad \sigma=\left\{\begin{array}{lll}
E \varepsilon_{e} & \text { if } & \sigma \leqslant \sigma_{y} \\
\sigma_{y}+k \varepsilon_{p}^{n} & \text { if } & \sigma>\sigma_{y}
\end{array}\right.
$$

with the hardening exponent $n$ and ductility coefficient $k$.

The mechanical proprieties of 5457-H111 aluminum alloy are summarized in Table 2.

As shown in Fig. 3, the true stress-strain results of 5457-H111 aluminum alloy are similar in the three directions. 
(a)

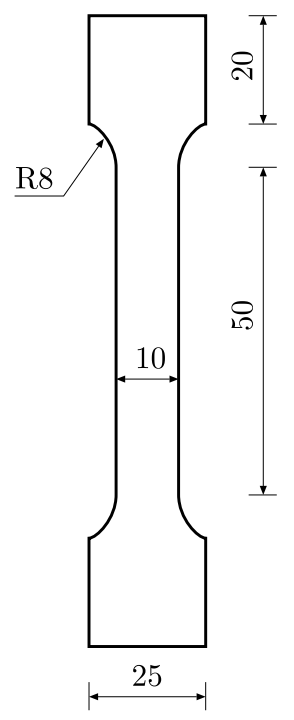

(b)

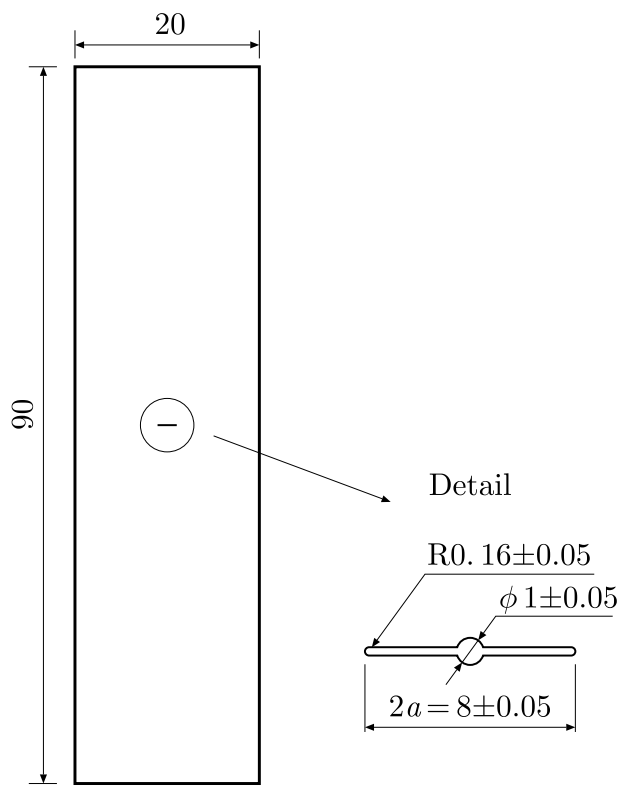

Fig. 2. (a) Geometry of the tensile specimen (in $\mathrm{mm}$ ), (b) dimensions of the CCP specimens (in $\mathrm{mm}$ )

Table 2. Mechanical proprieties of 5457-H111 aluminum alloy in three directions: $E$ - Young's modulus, $\sigma_{y}$-yield stress, $\sigma_{u}$ - ultimate stress, $A \%$ - elongation, $n$ - hardening exponent and $k$ - ductility coefficient

\begin{tabular}{|c|c|c|c|c|c|c|}
\hline & $E[\mathrm{MPa}]$ & $\sigma_{y}[\mathrm{MPa}]$ & $\sigma_{u}[\mathrm{MPa}]$ & $\delta[\%]$ & $n$ & $K[\mathrm{MPa}]$ \\
\hline \hline RD & 70612 & 100 & 270 & 15.28 & 0.586 & 575.554 \\
\hline TD & 70134 & 99 & 265 & 14.89 & 0.589 & 599.659 \\
\hline DD & 69978 & 98 & 259 & 15.13 & 0.580 & 590.034 \\
\hline
\end{tabular}

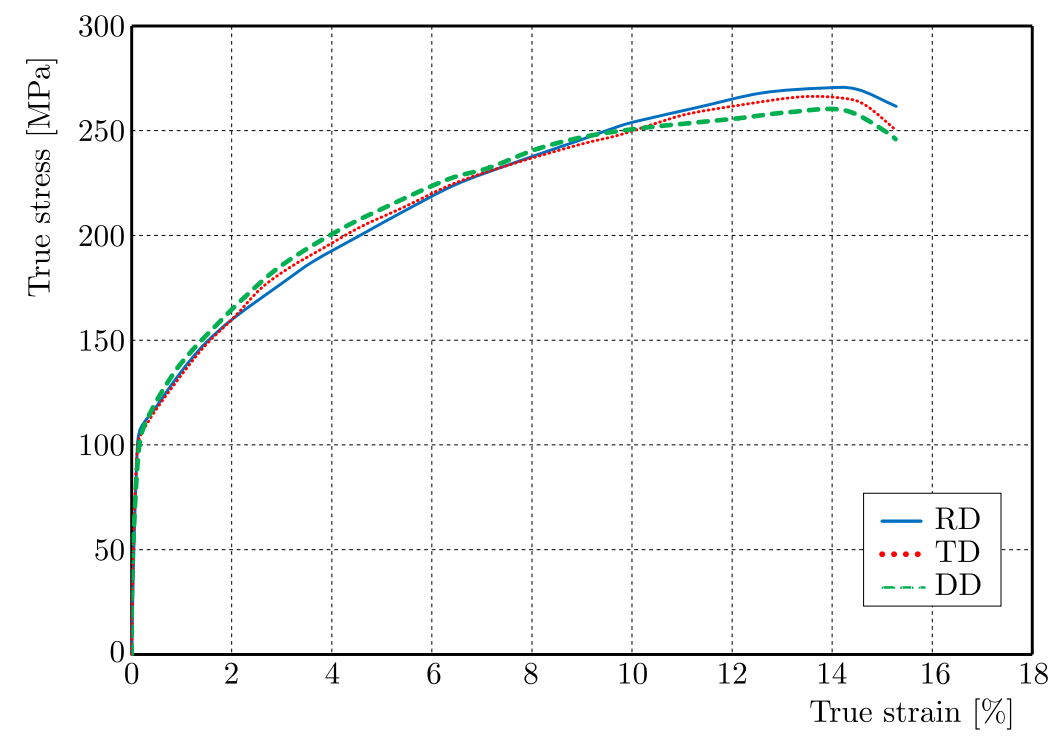

Fig. 3. Strain-stress curves of 5754-H111 aluminum alloy in the rolling direction (RD), transverse direction (TD) and diagonal direction (DD)

Ductile tearing tests were carried out on central cracked panels (CCP) at a constant displacement rate of $1 \mathrm{~mm} / \mathrm{min}$. The specimen geometry is presented in Fig. 2b. The ductile tearing specimens were manufactured in the rolling direction (RD) and transverse direction (TD) of the plates. In order to obtain a normalized crack length ratio $a / w$ equal to 0.36 , the specimens 
were pre-cracked by the fatigue test. These tests were achieved using the single specimen method (Taktak et al., 2009). Three specimens were operated at a constant cross-head speed of $1 \mathrm{~mm} / \mathrm{min}$.

The experimental load versus displacement curves of 5754-H111 aluminum alloy are exposed in Fig. 4. It is noted that these curves show a low experimental dispersion.

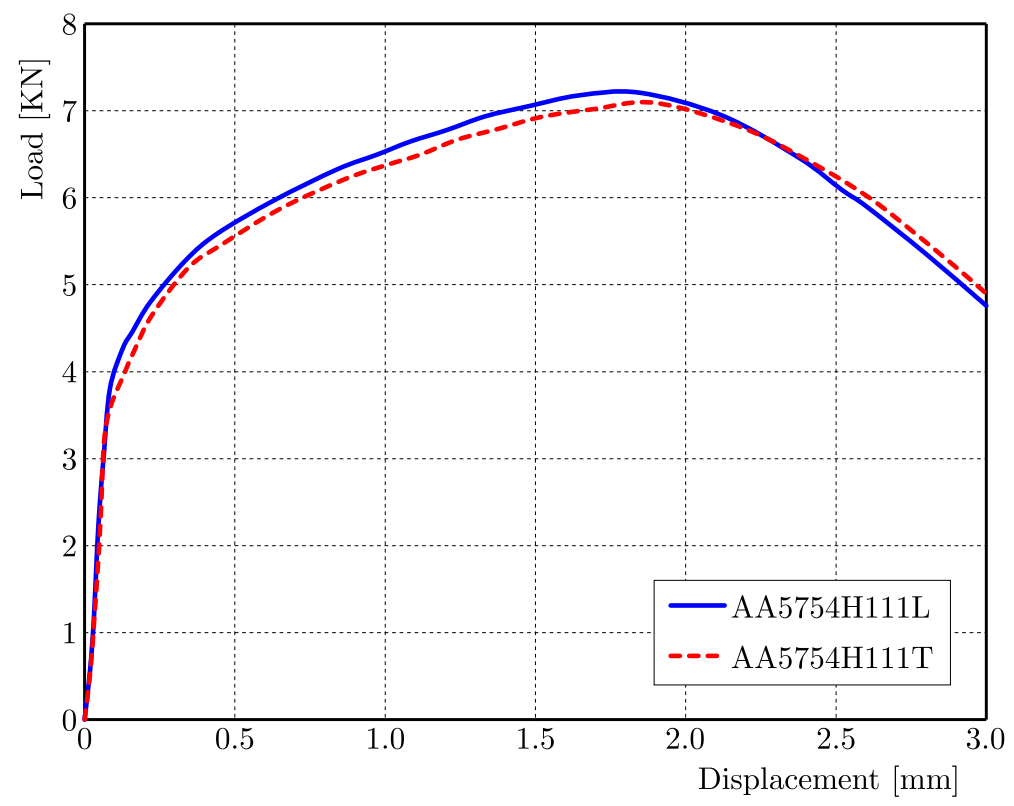

Fig. 4. Load versus displacement curves of 5754 aluminum alloy in the rolling direction (RD) and transverse direction (TD)

Also the fractographic examinations of 5754 aluminum alloy were performed on the fracture surfaces of the broken specimens from tensile testing by employing a scanning electron microscope (SEM). The SEM fractographs for 5754 aluminum alloy indicate the significant presence of ductile dimples (large voids beside smaller voids), which show the characteristic micro-void coalescence mechanism of ductile fracture (Fig. 5a-5d).

(a)

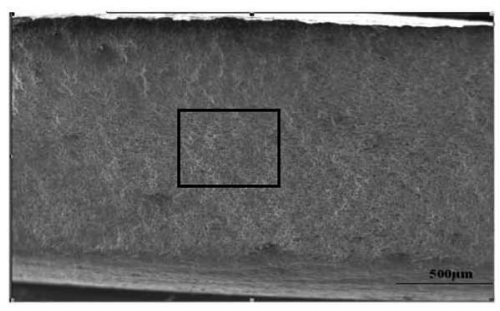

(c)

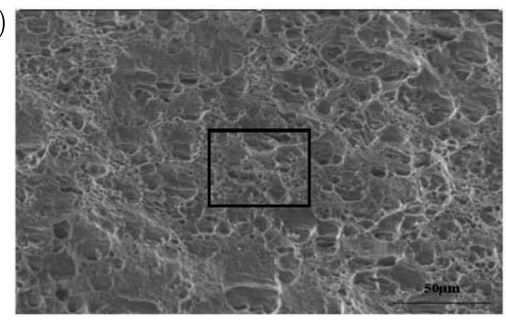

(b)

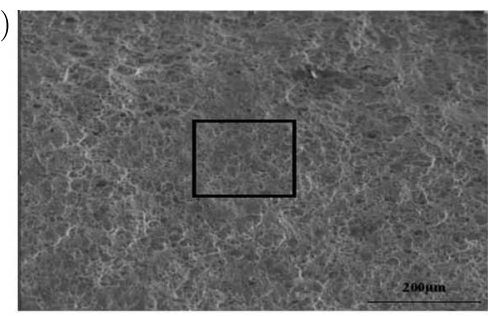

(d)

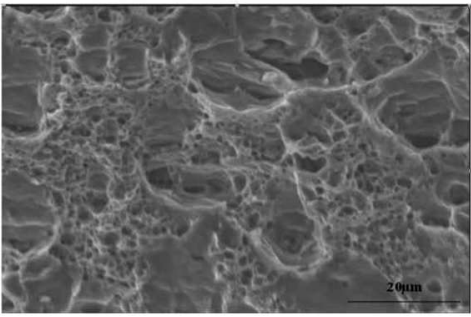

Fig. 5. SEM fractographs of the facture surface for a tensile specimen abstracted from 5754 aluminum alloys under different magnifications: $a$ overview morphology; $b$ extended image of indicated region of the picture (a), $c$ extended image of the indicated region of the picture (b), and $d$ extracted image of the indicated region of the picture (c) 


\section{Numerical analysis}

\subsection{The meshing and boundary conditions}

To obtain the theoretical force versus displacement curves, three-dimensional computation was performed using the finite element program ANSYS. In this study, the material is supposed to be elastoplastic, homogeneous and exhibit isotropic hardening. Two forms have been studied: the tensile specimen (Fig. 1a) and the CCP specimen (Fig. 1b). The meshing corresponding to each specimen using SOLID 185 finite element of ANSYS is presented in Fig. 6. The meshing near the crack tip consists of square mesh with $0.2 \mathrm{~mm}$ size (Taktak et al., 2008). All the nodes on the ligament in front of the crack tip are fully constrained to have a zero displacement in the $y$-direction normal to the plane of the crack. Due to symmetry, only a quarter of the tensile specimen (Fig. 6a) and CCP specimen (Fig. 6b) are modeled.

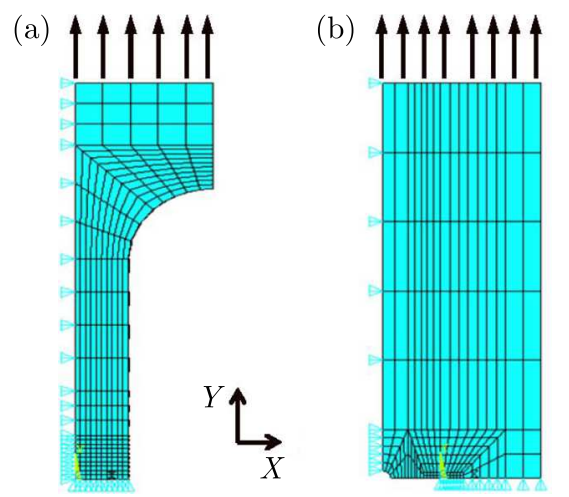

Fig. 6. (a) Meshing of a quarter of tensile specimen, (b) meshing of a quarter of the CCP specimen

\subsection{Identification of damage parameters}

The (GTN) ductile damage model has 9 necessary parameters: Three constitutive parameters related to the refined yield locus, $q_{1}, q_{2}$ and $q_{3}$, three void nucleation parameters $\varepsilon_{n}, S_{n}$ and $f_{n}$ and three parameters for void growth and coalescence $f_{0}, f_{c}$ and $f_{F}$. In the present investigation, seven parameters are determined by typical values proposed in literature (Tvergaard and Needleman, 1984; Lievers et al., 2004): $\varepsilon_{n}=0.65, S_{n}=0.03, f_{n}=0.00035, q_{1}=1.5, q_{2}=1$, $q_{3}=q_{1}^{2}=2.25$ and $f_{f}=0.25$. In accordance with the discussion in (Zhang et al., 2000; Rousselier, 2001), the critical void volume fraction $f_{c}$ can be chosen as 0.15 for aluminum alloys. Thus, only the initial volume fraction $f_{0}$ needs to be determined. Generally, in aluminum alloys, the void is made up of a fragile intermetallic phase (Ghahremaninezhad and Ravi-Chandar, 2012). The evaluation of the initial void volume fraction $f_{0}$ is obtained by metallorgraphic examination on a polished surface of undamaged materials. Also, $f_{0}$ is very little for this kinds of alloy. The initial void volume fraction $f_{0}$ can be estimated by the inverse finite element method using the finite element modeling and experiments. Guo et al. (2013) identified this parameter using the original Rousselier model to obtain three values of $f_{0} 0.0001,0.001,0.005$, respectively. By comparison with experimental results, he found a good agreement with $f_{0}=0.0001$ for AA5052. $\mathrm{Hu}$ et al. (2014) identified the parameter $f_{0}$ by an inverse method using experimental results. The simulations were done by setting the value of $f_{0}$ from 0.001 to 0.03 . The initial void volume fraction $f_{0}$ for AA 6016 equal 0.001 improved the good agreement between the simulation and experimental results.

In this work, to estimate the parameter $f_{0}$, an inverse method is used based on the FE method presented in this Section and the experimental results presented in Section 2. Six analyses have been made using the GTN model and the following initial void volume fraction $f_{0}: 0.00001$, 0.0001, 0.001, 0.01, 0.05 and 0.1, respectively. 


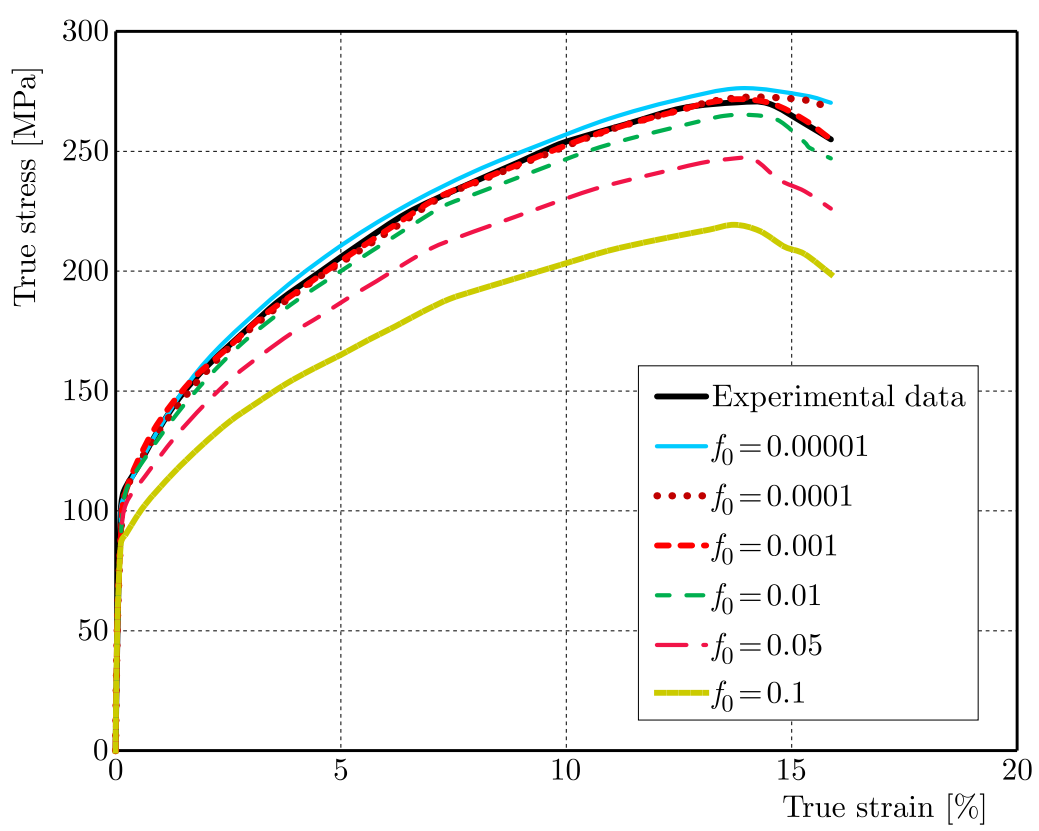

Fig. 7. The true stress-strain curves with different initial void volume fractions $f_{0}$ obtained by FE using the GTN model

The true stress-strain curves made by simulations with different $f_{0}$ are shown in Fig. 7 . It can also be shown that, for $f_{0}=0.001$, the difference between the simulation and experiment results is admissible. So, the initial void volume fraction $f_{0}$ was identified as 0.001 for this material. The whole GTN parameters of the material are now presented in Table 3.

Table 3. Calibrated parameters of the GTN model for the 5754-H111 aluminum alloy

\begin{tabular}{|c|c|c|c|c|c|c|c|c|}
\hline$q_{1}$ & $q_{2}$ & $q_{3}$ & $f_{0}$ & $f_{n}$ & $\varepsilon_{n}$ & $S_{n}$ & $f_{c}$ & $f_{f}$ \\
\hline \hline 1.5 & 1 & 2.25 & 0.001 & 0.00035 & 0.65 & 0.03 & 0.15 & 0.25 \\
\hline
\end{tabular}

To validate the identified parameters listed in Table 3, the experimental load versus displacement curve issued from tearing tests on the CCP specimen are compared with the simulated ones using these parameters in Fig. 8. A good agreement is observed between the experimental results and those prediced by the finite element method. This shows that the GTN parameters identified in this work are acceptable.

\section{Application to cold working effects}

In the preceding Sections, the ductile fracture model based on the GTN model has been found for 5754-H111 aluminum alloy. This model has many potential application domains: it can be used for predicting not only the failure behavior of ductile tearing tests specimens but also for predicting size effects of ductile tearing tests specimens. The application of 5754-H111 aluminum alloy in automotive industry needs a high strength/weight ratio (Burger et al., 1995). So, it is possible to carry out the strain hardening in the rolling direction. In the literature, many experimental investigations have been published on quantification of the strain hardening impact on mechanical cold working fracture properties for aluminum alloys. Our essential interest in this Section is the application and validation of the identified GTN model to measure cold working effects on numerical simulation. Tests were carried to measure the cold working effects on tensile and ductile tearing proprieties of 5754-H111 aluminum alloy. In these tests, the used material was 


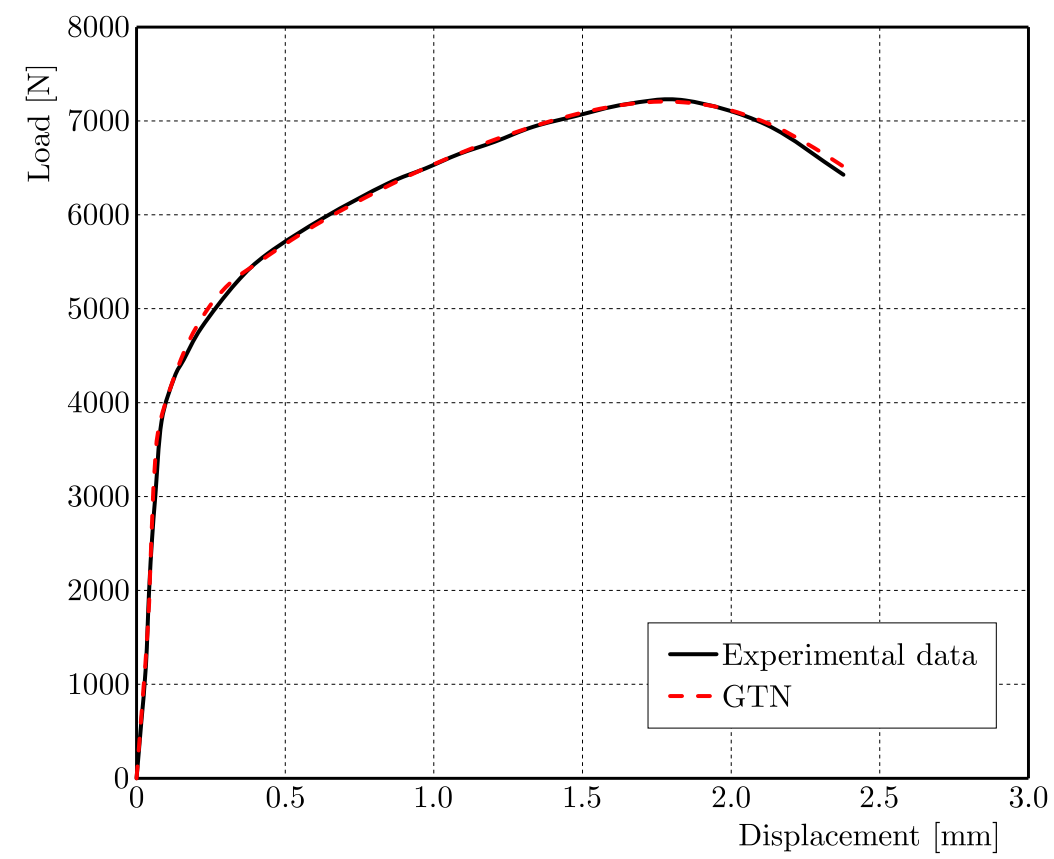

Fig. 8. Load versus displacement. Comparison between the experiment and FE simulation for the GTN model

similar condition to the one used in the previous Sections. A plate of the alloy (with thickness of $2.45 \mathrm{~mm}$, width $150 \mathrm{~mm}$ and length of $150 \mathrm{~mm}$ ) was cold rolled by a laboratory rolling mill to the reduction of $25 \%$ and $50 \%$ in area $(\mathrm{CW}=25 \%$ and $\mathrm{CW}=50 \%)$.

Both the tensile and CCP specimens were abstracted from the plate in the longitudinal direction. The experimental conditions and geometry of the tensioned specimen and ductile tearing tests were same as those in the previous Sections. The tensile properties of the material subjected to different cold working rates are summarized in Table 4. It shows that the yield and tensile strength increase with the increasing percent of cold working, but the ductility decreases (Cosham, 2001; Mansourinejad and Mirzakhani, 2012). The strengthening of the material can be described by the increase of dislocation density with plastic deformation. The average distance between dislocations decreases and the dislocations start blocking motion of each other (Hajizadeh et al., 2014).

It is widely acknowledged that the cold working effect on tensile curves can be quantified simply by shifting the true strain-stress curve by an increase of cold working (Ainsworth, 1986; Cosham, 2001), which is carried out by analyzing the present experimental results, as shown in Fig. 9.

Table 4. Main mechanical characteristics for different cold working rates: $E$ - Young's modulus, $\sigma_{y}$ - yield stress, $\sigma_{u}-$ ultimate stress, $A \%$ - elongation

\begin{tabular}{|c|c|c|c|c|}
\hline CW & $E[\mathrm{MPa}]$ & $\sigma_{y}[\mathrm{MPa}]$ & $\sigma_{u}[\mathrm{MPa}]$ & $A[\%]$ \\
\hline \hline $0 \%$ & 70612 & 100 & 270 & 15.28 \\
\hline $25 \%$ & 71334 & 168 & 278 & 7.50 \\
\hline $50 \%$ & 69789 & 190 & 307 & 5.29 \\
\hline
\end{tabular}

As shown in Fig. 10, the values of the hardening exponent $n$ and ductility coefficient $k$ are similar in the two directions. For this reason, we can consider that the behavior of these work-hardened materials is isotropic. 


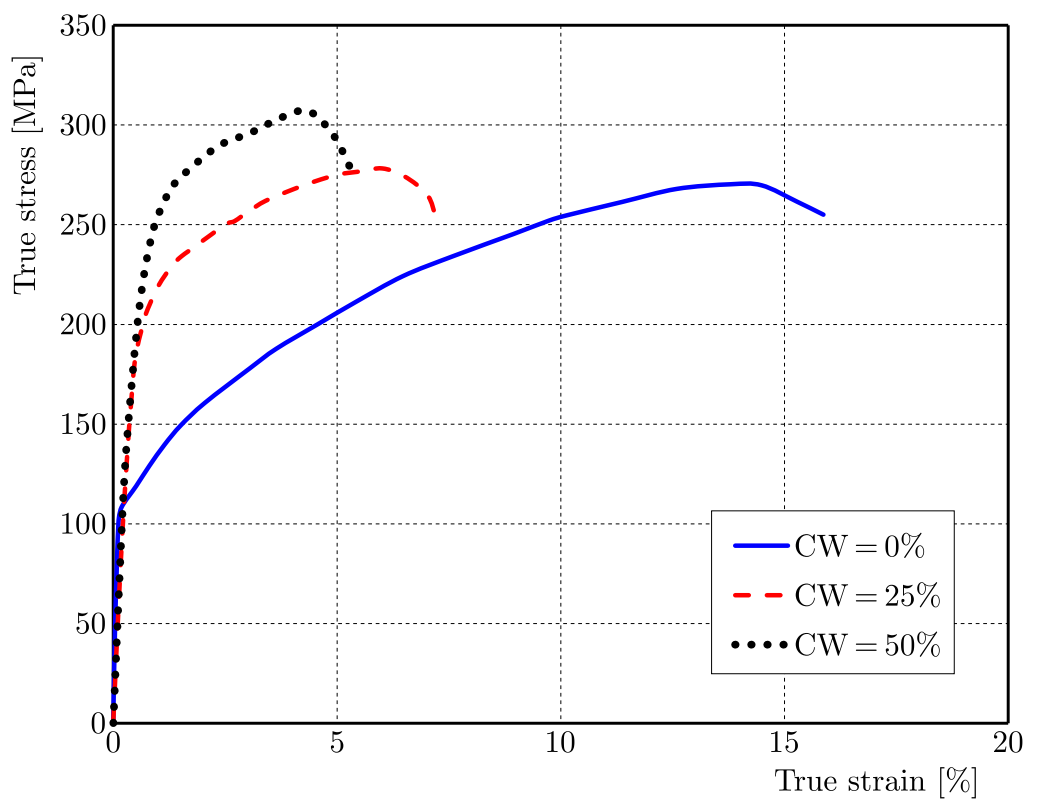

Fig. 9. Experimental results of the cold working effect on tensile curves

(a)

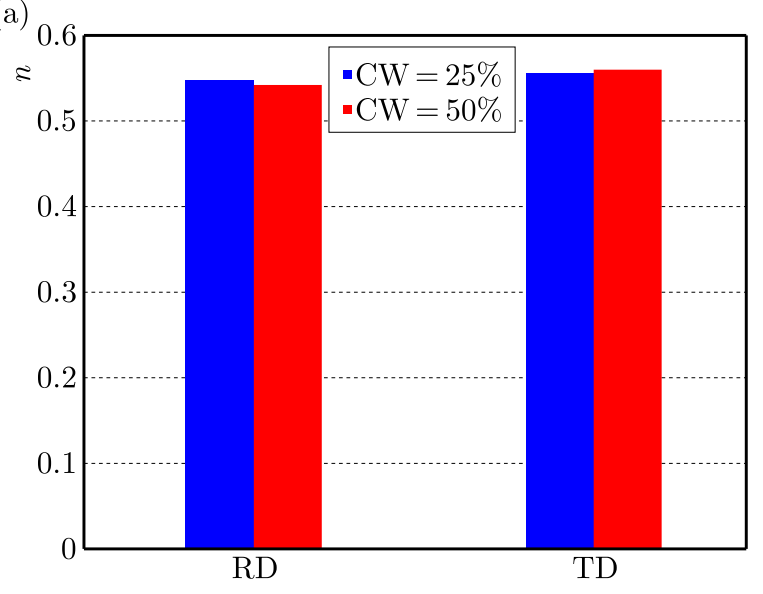

(b)

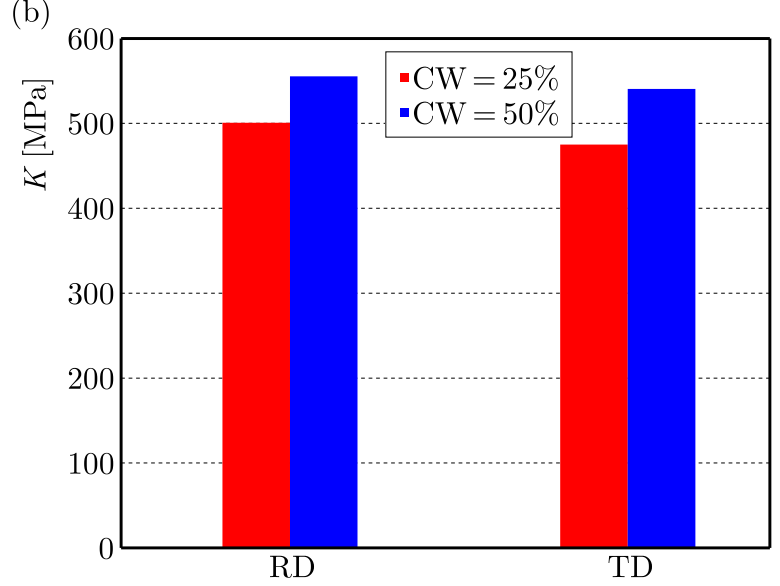

Fig. 10. Values of the hardening exponent $n$ and ductility coefficient $k$ in the rolling direction (RD), transverse direction (TD)

The SEM pictures of the cold worked specimens indicated a fine network of dimples (elongated voids with the fibrous structure) and little quasi-cleavage parts corresponding to the ductile fragile failure mechanism when the percentage of cold working increases (shown in Fig. 11). Generally, in FCC metals like 5457-H111 aluminum alloys, even at low temperature, the dislocation of leavings is important and the material rests ductile enough.

Thus, the morphology of fracture ought to be fundamentally fibrous plus some cleavage, reflecting the fragile failure behavior of the alloys when the percentage of cold working high.

The experimental load-displacement curves are summarized in Fig. 12. It indicates that the maximum loads for cold working are lower than those for without cold working.

Using the overhead information, finite element damage analyses based on the GTN model are used for simulating tensile tests and ductile tearing using ANSYS. To incorporate cold working into finite element damage analyses, two modifications are added. First, the true stress-strain curve is modified according to cold working. Secondly, the value of the initial void volume fraction $f_{0}$ is changed (Oh et al., 2007). As noted, the value of the initial void volume fraction $f_{0}$ increases when the cold working rate increases (Oh et al., 2007). 
(a)

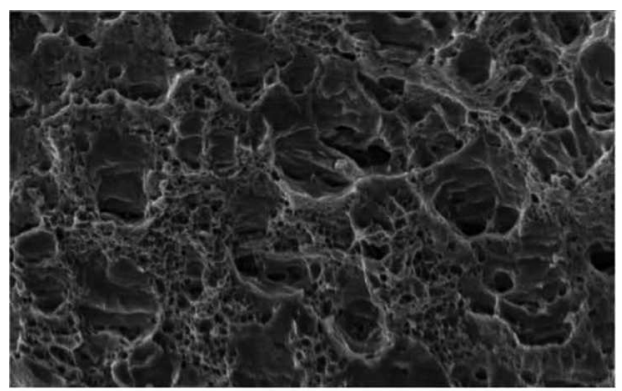

(b)

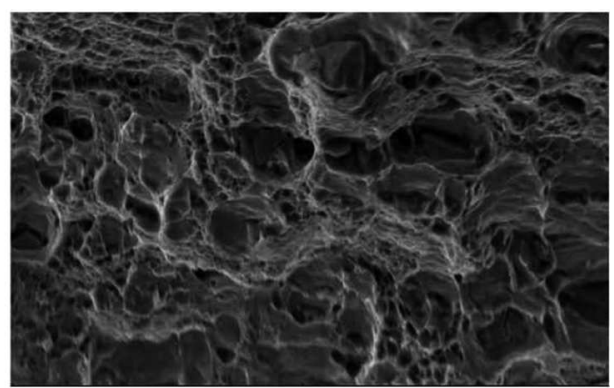

(c)

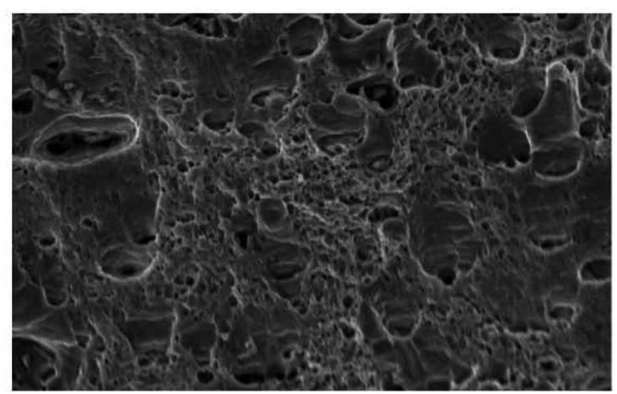

Fig. 11. SEM fractographs of 5457 aluminum alloy at different percentage of cold working: (a) $0 \%$, (b) $25 \%$ and (c) $50 \%$

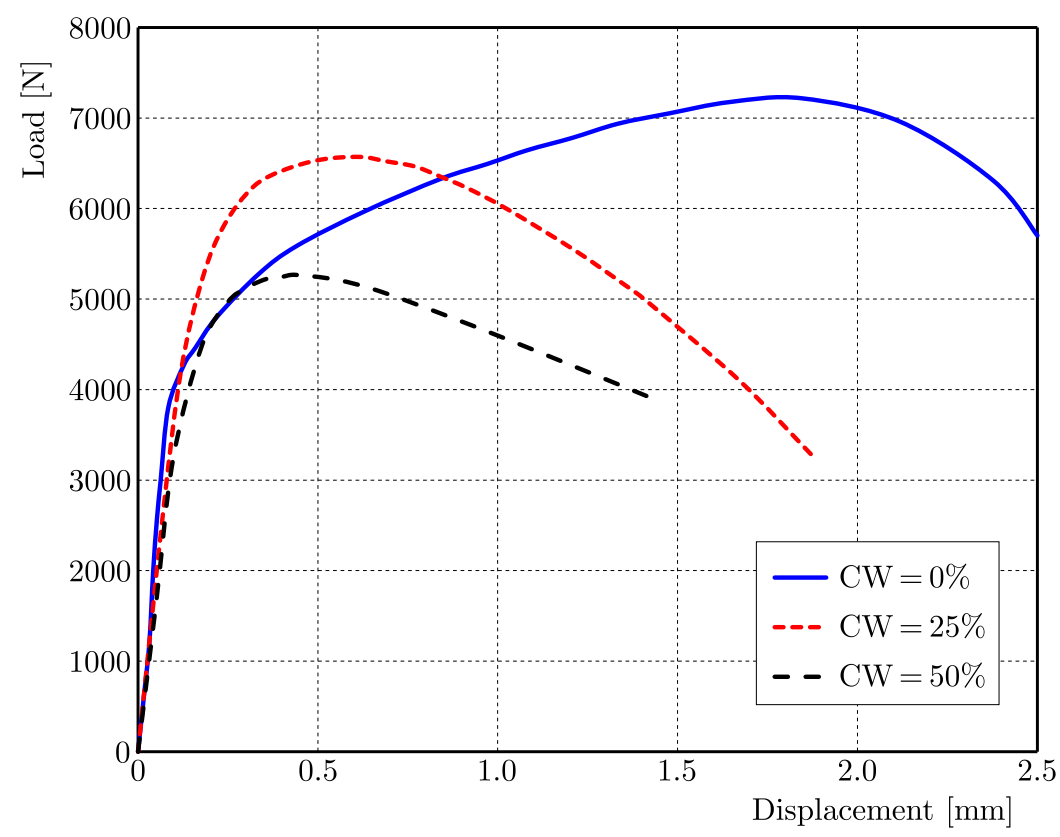

Fig. 12. Experimental results of cold working effects on load versus displacement curves

Figure 13 compares the experimental true stress-strain results with the numerical ones from finite element damage analyses based on the GTN model for different choices of $f_{0}$ for selected cases $(\mathrm{CW}=25 \%$ and $50 \%)$.

From Figs. 13a and 13b, it can be seen that the choice of $f_{0}=0.006$ and $f_{0}=0.009$ for the cold working rate $25 \%$ and $50 \%$, respectively, enables achieving the best agreement between the (FE) damage analyses and experimental results.

For validation, the results from finite element damage analyses for cold working rates $25 \%$ and $50 \%$ are compared with the experimental load-displacement curves, and reasonably good comparisons are found. It is shown in Fig. 14. 
(a)

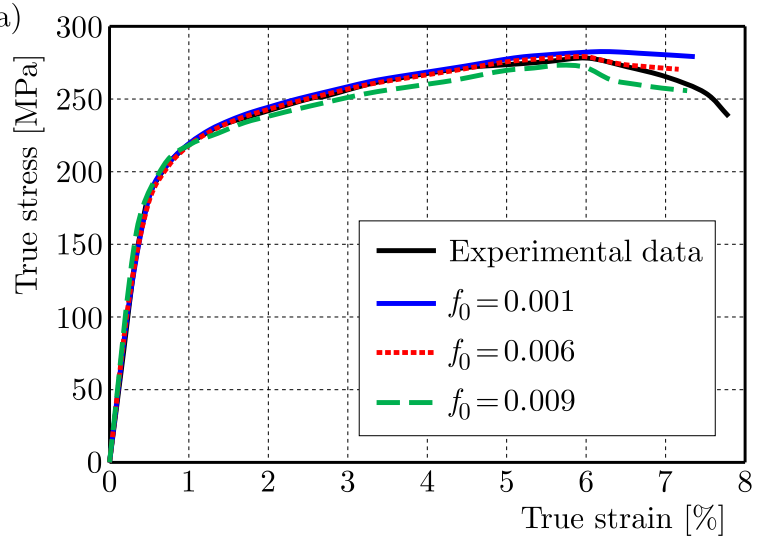

(b)

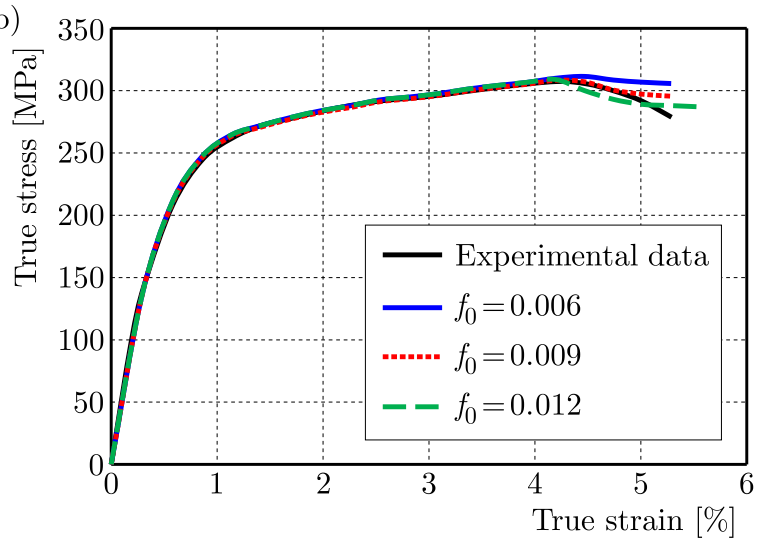

Fig. 13. True stress-strain curves with different initial void volume fractions $f_{0}$ obtained by FE using the GTN model. (a) The initial void volume fraction $f_{0}$ is calibrated as 0.006 for $\mathrm{CW}=25 \%$. (b) The initial void volume fraction $f_{0}$ is calibrated as 0.009 for $\mathrm{CW}=50 \%$
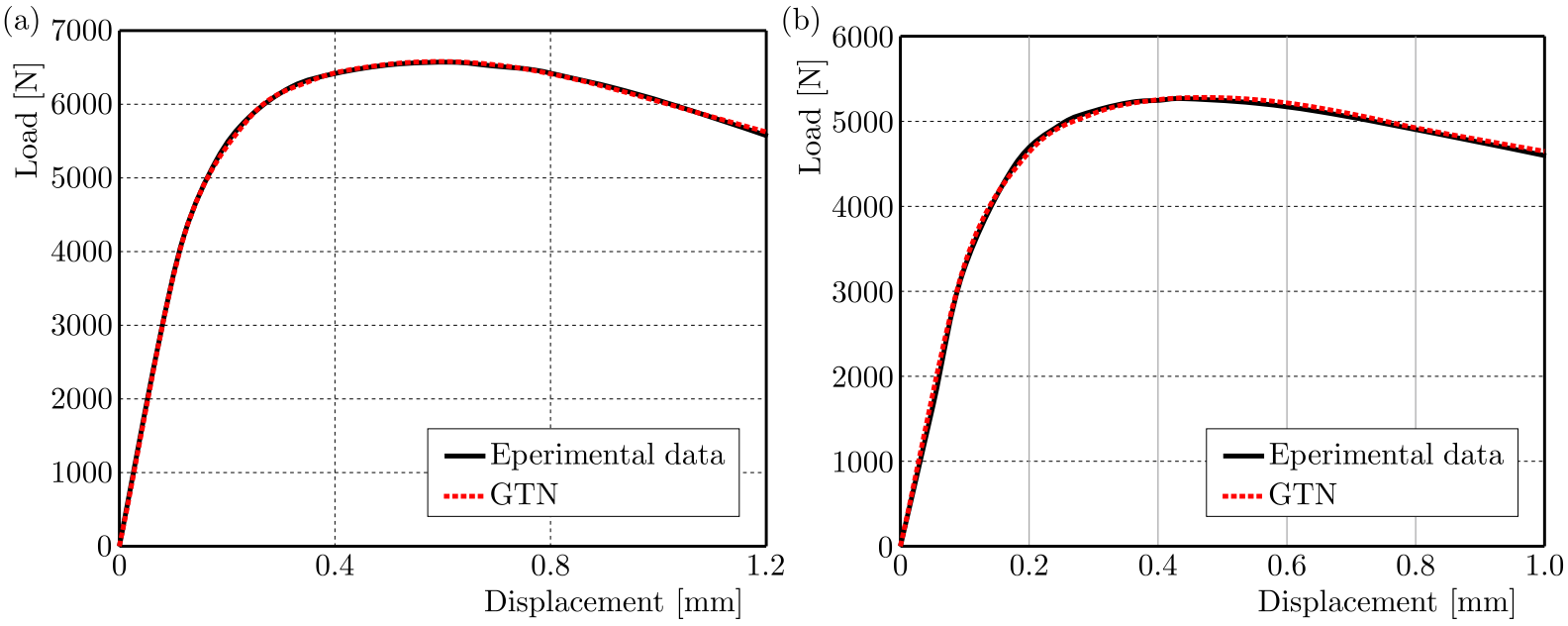

Fig. 14. Comparisons of FE simulations with experiments for the load versus displacement curves (a) $\mathrm{CW}=25 \%$, (b) $\mathrm{CW}=50 \%$

The results show that the experimental tensile tests and load versus displacement have been successfully predicted by the GTN model, and can take into account the cold working effect not only on plastic deformation but also on ductile fracture.

\section{Summary and conclusions}

- The continuum damage mechanics model (GTN) has been used to simulate the ductile tearing behavior of 5754-H111 aluminum alloy sheet metal.

- The parameters of the GTN model have been identified by an experimental tensile test (true stress versus true strain) and the inverse finite element method.

- The validity of the proposed parameters has been investigated by comparing the simulated results with the experimental ones from the tensile and ductile tearing tests (load versus displacement).

- The determined GTN model has been applied to predict the cold working influence on deformation and fracture. Comparison of experimental data of cold working, tensile tests and ductile tearing tests with finite element damage analyses have shown good agreements. 


\section{References}

1. Achouri M., Germain G., Dal Santo P., Saidane D., 2012, Implementation and validation of a Gurson damage model modified for shear loading: effect of void growth rate and mesh size on the predicted behavior, Key Engineering Materials, 504, 691-696

2. Ainsworth R.A., 1986, An assessment of the effects of prestrain on upper shelf fracture toughness, The Journal of Strain Analysis for Engineering Design, 21, 219-224

3. Benseddiq N., Imad A., 2007, A ductile fracture analysis using a local damage model, International Journal of Pressure Vessels and Piping, 85, 219-227

4. Betegon C., Rodriguez C., Belzunce F.J., 1997, Analysis and modelisation of short crack growth by ductile fracture micromechanisms, Fatigue and Fracture of Engineering Material and Structures, 20, 633-644

5. Burger G.B., Gupta A.K., Jeffrey P.W., Lloyd D.J., 1995, Microstructural control of aluminum sheet used in automotive applications, Materials Characterization, 35, 23-39

6. Cosham A., 2001, A model of pre-strain effects on fracture toughness, Journal of Offshore Mechanics and Arctic Engineering, 123, 182-190

7. Corigliano A., Mariani S., Orsatti B., 2000, Identification of Gurson-Tvergaard material model parameters via Kalman filtering technique. I. Theory, International Journal of Fracture, 104, 349-373

8. Ghahremaninezhad A., Ravi-Chandar K., 2012, Ductile failure behavior of polycrystalline Al 6061-T6, International Journal of Fracture, 174, 177-202

9. Guo J., Zhao S., Murakami R.I., Zang S., 2013, Experimental and numerical investigation for ductile fracture of Al-alloy 5052 using modified Rousselier model, Computational Materials Science, 71, 115-123

10. Gurson A.L., 1977, Continuum theory of ductile rupture by void nucleation and growth: Part I - Yield criteria and flow rules for porous ductile media, Journal of Engineering Materials and Technology, 99, 2-15

11. Hajizadeh K., Tajall M., Emadoddin E., Borhani E., 2014, Study of texture, anisotropy and formability of cartridge brass sheets, Journal of Alloys and Compounds, 588, 690-696

12. Hu Y.M., Chen M.Z., Xiao Y., Xiao J., Tan X., Tang Q., Cui T.S., 2014, Parameters determination of GTN model and damage analysis of aluminum alloy 6016 sheet, International Conference on Material Science and Applications (ICMSA-15), Atlantis Press

13. Huang X.-C., Chen Y.-Z., Chen Y.-M., Niu W., 2007, Identification of mesodamage parameters of 2169 steel, Journal of Materials Engineering, 4, 50-52

14. Imad A., Wilsius J., Abdelaziz M.N., Mesmacque G., 2003, Experiments and numerical approaches to ductile tearing in an 2024-T351 aluminium alloy, International Journal of Mechanical Sciences, 45, 1849-1861

15. Lievers W.B., Pilkey A.K., Lloyd D.J., 2004, Using incremental forming to calibrate a void nucleation model for automotive aluminum sheet alloys, Acta Materialia, 52, 3001-3007

16. Mansourinejad M., Mirzakhani B., 2012, Influence of sequence of cold working and aging treatment on mechanical behaviour of 6061 aluminum alloy, Transactions of Nonferrous Metals Society of China, 22, 2072-2079

17. MCClintock F.A., 1968, A criterion for ductile fracture by the growth of holes, Journal of Applied Mechanics, 35, 363-371

18. Он C.K., Kim Y.J., BAeK J.H., Kim Y.P., 2007, A phenomenological model of ductile fracture for API X65 steel, International Journal of Mechanical Sciences, 49, 1399-1412

19. Rice J.R., Tracey D.M., 1969, On the ductile enlargement of voids in triaxial stress fields, Journal of the Mechanics and Physics of Solids, 17, 201-217 
20. Rousselier G., 2001, The Rousselier model for porous metal plasticity and ductile fracture, Handbook of Materials Behavior Models, 2, 436-445

21. TAktak R., Benseddiq N., Imad A., 2009, Analysis of ductile tearing using a local approach to fracture, Fatigue and Fracture of Engineering Materials and Structures, 32, 525-530

22. TVergaArd V., 1981, Influence of voids on shear band instabilities under plane strain conditions, International Journal of Fracture, 17, 389-407

23. Tvergandd V., Needleman A., 1984, Analysis of the cup-cone fracture in a round tensile bar, Acta Metallurgica, 32, 157-169

24. Yan Y., Sun Q., Chen J., PAn H., 2013, The initiation and propagation of edge cracks of silicon steel during tandem cold rolling process based on the Gurson-Tvergaard-Needleman damage model, Journal of Materials Processing Technology, 213, 598-605

25. Zhang Z.L., Thaulow C., Odegard, 2000, A complete Gurson model approach for ductile fracture, Engineering Fracture Mechanics, 67, 155-168

Manuscript received October 14, 2016; accepted for print March 31, 2017 